\section{Poultry Infection with Influenza Viruses of Wild Bird Origin, China, 2016}

\author{
Zhijun Yu, ${ }^{1}$ Kaihui Cheng, ${ }^{1}$ Yuwei Gao ${ }^{1}$
}

Author affiliations: Institute of Poultry Science of Shandong Academy of Agricultural Sciences, Jinan, China (Z. Yu); Shandong Academy of Agricultural Sciences, Jinan (Z. Yu, K. Cheng); Dairy Cattle Research Center of Shandong Academy of Agricultural Sciences, Jinan (K. Cheng); Military Veterinary Research Institute of Academy of Military Medical Sciences, Changchun, China (Y. Gao)

DOI: https://doi.org/10.3201/eid2407.171220

Migratory birds may play a role in transmission of avian influenza virus. We report the infection of black-tailed gulls and chickens in eastern China with avian influenza (H13N2) and $(\mathrm{H} 13 \mathrm{~N} 8)$ viruses. We found that these $\mathrm{H} 13$ viruses were transmitted from migratory birds to domestic poultry.

$\mathrm{A}$ vian influenza virus with 10 hemagglutinin (HA) subtypes has emerged in poultry (1), and the potential role of migratory birds in transmission of avian influenza virus has caused concern (2). We report infection with low pathogenicity avian influenza (LPAI) virus of HA subtype 13 (H13) among migratory birds (black-tailed gulls [Larus crassirostris]) and domestic poultry (chickens) in Weihai, Shandong Province, eastern China (online Technical Appendix Figure 1, https://wwwnc.cdc.gov/EID/ article/24/7/17-1220-Techapp1.pdf).

Weihai is a breeding center for black-tailed gulls that congregate from northern Asia, eastern Asia, Southeast Asia, and North America. These gulls reside along the coastlines of the East China Sea and Japan and have been found as vagrants in Alaska, North America, and the Philippines (3). In China, black-tailed gulls perch at the Longxudao wharf $\left(37^{\circ} 23^{\prime} 24.05^{\prime \prime} \mathrm{N}, 122^{\circ} 41^{\prime} 26.16^{\prime} \mathrm{E}\right)$, located in the northeastern corner of Weihai. In December 2016, we collected 149 fecal samples from black-tailed gulls at Longxudao wharf and screened them for evidence of influenza virus by reverse transcription PCR, DNA sequencing, and BLAST (http://www.ncbi.nlm.nih.gov/blast/Blast.cgi) analysis in the GenBank database. After independently inoculating positive fecal samples into the allantoic cavities of specific pathogenfree embryonated chicken eggs, we obtained 6 influenza $\mathrm{H} 13 \mathrm{~N} 2$ and 60 influenza H13N8 virus isolates.

To assess the epidemiologic characteristics of these $\mathrm{H} 13$ isolates, we completely sequenced an H13N2 isolate (A/black-tailed gull/Weihai/115/2016) and an H13N8

${ }^{1}$ All authors contributed equally to this article. isolate (A/black-tailed gull/Weihai/17/2016) (GenBank accession nos. MF461177-92). Phylogenetic analysis indicated that their HA and neuraminidase (NA) segments were derived from the Eurasian lineage, in accordance with their geographic distribution (online Technical Appendix Figures 2, 3). Moreover, the H13N2 and H13N8 isolates possessed high nucleotide sequence identity to the avian influenza virus subtypes previously isolated from Europe, Asia, and North America (online Technical Appendix Table 1). We speculate that avian influenza virus subtypes H13N2 and H13N8 are reassortants between the Eurasian and North American lineages (online Technical Appendix Figures 4, 5).

We next analyzed the timing of the reassortment events that led to the emergence of subtype H13N2 (Figure, panel A). During July 2009, June 2012, July 2009, and June 2015, the following genes, respectively, were transferred from seagulls in Europe: HA, nucleocapsid protein (NP), matrix (M), and nonstructural (NS). During 2004, November 2011, and October 2014, the following genes, respectively, originated from waterfowl in Asia: polymerase basic (PB) 1, polymerase acidic (PA), and NA. In November 2007, the PB2 gene was transferred from avian influenza viruses circulating among wild waterfowl in North America.

We also estimated the timing of the reassortment events that led to the emergence of subtype H13N8 (Figure, panel B). During June 2012, July 2013, July 2013, and June 2015, the following genes, respectively, were transferred from seagulls in Europe: NP, NA, M, and NS. During 2004, November 2011, and September 2012, the following genes, respectively, originated from waterfowl in Asia: PB1, PA, and HA. In November 2007, the PB2 gene was transferred from avian influenza viruses circulating among wild waterfowl in North America.

According to these data, the generation of influenza virus subtypes H13N2 and H13N8 in seagulls seems to have been a complex process and was probably completed in the middle of 2015 (Figure). We also found that subtypes H13N2 and H13N8 possessed some molecular markers associated with increased virulence and transmission among mammals (online Technical Appendix Table 2).

In April 2017, we analyzed serum samples collected from 48 chickens at a chicken farm at Songcun town $\left(37^{\circ} 04^{\prime} 39.96^{\prime \prime} \mathrm{N}, 122^{\circ} 00^{\prime} 38.83^{\prime \prime} \mathrm{E}\right)$ in Weihai for serologic evidence of exposure to H13 viruses. We found detectable hemagglutinin inhibition (HI) antibody titers against $\mathrm{H} 13 \mathrm{~N} 2$ virus in $4(8.3 \%)$ samples and detectable $\mathrm{HI}$ antibody titers against $\mathrm{H} 13 \mathrm{~N} 8$ virus in $14(29.2 \%)$ samples (online Technical Appendix Table 3). When we evaluated reference serum samples known to contain $\mathrm{HI}$ antibodies against each of the virus subtypes for potential cross-reactivity, we observed no apparent cross-reactivity of H13 


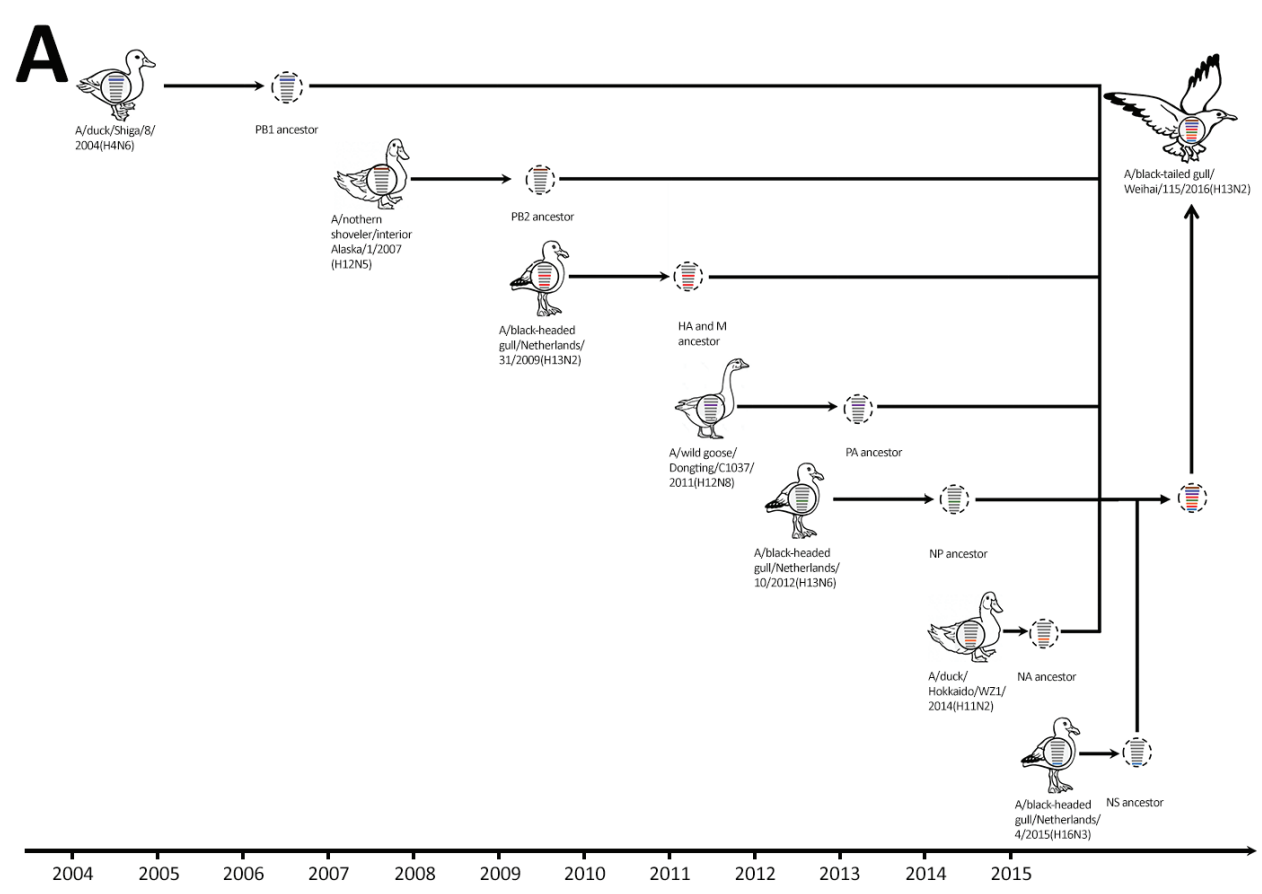

Figure. Hypothetical evolutionary pathway of avian influenza viruses of $\mathrm{H} 13 \mathrm{~N} 2(\mathrm{~A})$ and $\mathrm{H} 13 \mathrm{~N} 8$ virus (B) subtypes isolated from black-tailed gulls in eastern China, 2016. Dashed virions indicate unidentified viruses. $H A$, hemagglutinin; $M$, matrix protein; NA, neuraminidase; NP, nucleoprotein; NS, nonstructural protein; PA, polymerase acidic protein; $\mathrm{PB}$, polymerase basic protein. A color version of this figure showing gene segments origins is available online (https://wwwnc.cdc.gov/EID/ article/24/7/17-1220-F1.htm).

B
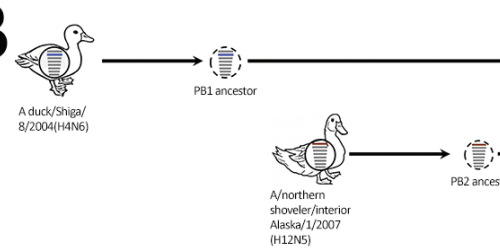

antibodies against 7 other HA subtype viruses (online Technical Appendix Table 6). Therefore, although the serum samples' HI antibody titers against H13 viruses were not high, we cannot exclude the possibility that these antibodies were generated in response to independent exposure to $\mathrm{H} 13$ viruses.

In March 2013, the novel LPAI H7N9 virus causing serious human infections was detected in eastern China (4-7); after circulating among domestic poultry, this virus evolved into a highly pathogenic virus (8). Therefore, enhanced surveillance is needed to determine whether other LPAI viruses could be introduced into domestic poultry and pose a threat to public health.

In this study, we isolated a large number of LPAI H13 viruses from seagulls at the Longxudao wharf and detected H13-specific seroconversion in chickens at a chicken farm, which is $\approx 100 \mathrm{~km}$ west of this wharf and lies on the migratory route of black-tailed gulls. These findings indicate 
that $\mathrm{H} 13$ viruses may have been introduced into domestic poultry from migratory birds and that they may have the potential to become a global cross-species threat.

This work was supported by the Youth Foundation of the Natural Science Foundation of Shandong Province (ZR2018QC005), the High-Level Talents and Innovative Team Recruitment Program of the Shandong Academy of Agricultural Sciences, the Special Fund of Institute Development (1-08-040 and 1-08-043), the construction of the discipline team for the Institute of Poultry Science (1-18-015), the National Key Technology Research and Development Program (2013BAD12B04), and the National Key Research and Development Plan (2016YFD0500203 and 2017YFD0500100).

\section{About the Author}

Dr. Yu is a chief of the Monitoring and Early Warning Platform for Cross-species and Virus-induced Diseases in Livestock and Poultry at the Institute of Poultry Science, Shandong Academy of Agricultural Sciences, Jinan, China. His research interests include the epidemiology and evolutionary mechanisms of influenza viruses, the pathogenesis of influenza viruses, and the innate host antiviral immune response.

\section{References}

1. Su S, Bi Y, Wong G, Gray GC, Gao GF, Li S. Epidemiology, evolution, and recent outbreaks of avian influenza virus in China. J Virol. 2015;89:8671-6. http://dx.doi.org/10.1128/JVI.01034-15

2. Global Consortium for $\mathrm{H} 5 \mathrm{~N} 8$ and Related Influenza Viruses. Role for migratory wild birds in the global spread of avian influenza H5N8. Science. 2016;354:213-7. http://dx.doi.org/10.1126/ science.aaf8852

3. Kim JY, Park YC. The complete mitogenome of the black-tailed gull Larus crassirostris (Charadriiformes: Laridae). Mitochondrial DNA A DNA Mapp Seq Anal. 2016;27:1885-6. http://dx.doi.org/ 10.3109/19401736.2014.971271 PMID: 25319297

4. Belser JA, Gustin KM, Pearce MB, Maines TR, Zeng H, Pappas C, et al. Pathogenesis and transmission of avian influenza A (H7N9) virus in ferrets and mice. Nature. 2013;501:556-9. http://dx.doi.org/10.1038/nature12391

5. Gao R, Cao B, Hu Y, Feng Z, Wang D, Hu W, et al. Human infection with a novel avian-origin influenza A (H7N9) virus. N Engl J Med. 2013;368:1888-97. http://dx.doi.org/10.1056/ NEJMoa1304459

6. Lam TT, Wang J, Shen Y, Zhou B, Duan L, Cheung CL, et al. The genesis and source of the H7N9 influenza viruses causing human infections in China. Nature. 2013;502:241-4. http://dx.doi.org/10.1038/nature12515

7. Zhang Q, Shi J, Deng G, Guo J, Zeng X, He X, et al. H7N9 influenza viruses are transmissible in ferrets by respiratory droplet. Science. 2013;341:410-4. http://dx.doi.org/10.1126/science.1240532

8. Ke C, Mok CKP, Zhu W, Zhou H, He J, Guan W, et al. Human infection with highly pathogenic avian influenza $\mathrm{A}(\mathrm{H} 7 \mathrm{~N} 9)$ virus, China. Emerg Infect Dis. 2017;23:1332-40. http://dx.doi.org/10.3201/eid2308.170600

Address for correspondence: Zhijun Yu, Shandong Academy of Agricultural Sciences, Institute of Poultry Science, No. 1 Jiaoxiao Rd, Jinan, 250023, China; email: zhijun0215@gmail.com

\section{Rat-Bite Fever in Human with Streptobacillus notomytis Infection, Japan}

\author{
Yoshihiko Ogawa, Kei Kasahara, Sang-Tae Lee, \\ Takamitsu Ito, Hideo Hasegawa, Sachie Hirose, \\ Shigeru Santo, Atsushi Yoshida, Ryuichi Nakano, \\ Hisakazu Yano, Keiichi Mikasa
}

Author affiliations: Nara Medical University, Nara, Japan (Y. Ogawa, K. Kasahara, S.T. Lee, (R. Nakano, H. Yano) K. Mikasa); Osaka Gyoumeikan Hospital, Osaka, Japan (T. Ito, H. Hasegawa, S. Hirose, S. Santo, A. Yoshida)

DOI: https://doi.org/10.3201/eid2407.171580

We report a case of rat-bite fever in a 94-year-old woman with Streptobacillus notomytis infection. We established an epidemiologic link between exposure to rats and human infection by performing nested PCRs that detected S. notomytis in the intraoral swab specimens obtained from rats captured in the patient's house.

Streptobacillus is a genus of gram-negative, filamentous, $\mathcal{N}$ rod-shaped bacilli belonging to the family Leptotrichiaceae. Since 2014, four novel species other than S. moniliformis have been reported: $S$. hongkongensis was isolated from 2 human patients, $S$. felis from the lung of a cat, $S$. ratti from black rats, and $S$. notomytis from a spinifex hopping mouse (1-4). We report a case of a human infection with $S$. notomytis.

A 94-year-old woman sought treatment at our hospital for general malaise, anorexia, and bilateral knee pain. At admission, her body temperature was $38^{\circ} \mathrm{C}$; physical examination revealed swelling in both knees. Her skin was intact, with no rashes or animal bites. Laboratory tests revealed high leukocyte count $\left(1.42 \times 10^{9}\right.$ cells $\left./ \mathrm{L}\right)$ and elevated level of C-reactive protein $(19.5 \mathrm{mg} / \mathrm{dL})$.

Bilateral knee arthrocentesis yielded $25 \mathrm{~mL}$ of purulent fluid; Gram stain demonstrated the presence of few, thin, gram-negative bacilli with pyrophosphate calcium crystals and neutrophils (Figure). Bacterial culture yielded transparent, small, smooth colonies on $5 \%$ sheep blood agar (Kyokuto, Tokyo, Japan) incubated at $37^{\circ} \mathrm{C}$ under $5 \%$ $\mathrm{CO}_{2}$ for $48 \mathrm{~h}$. However, the automated bacterial identification method (Vitek 2; bioMérieux, Tokyo, Japan) failed to identify the isolate. We evaluated the isolate (NR2245) by matrix-assisted laser desorption/ionization time-offlight mass spectrometry using Bruker MALDI BioTyper software version 4.001 library database (Bruker Daltonik $\mathrm{GmbH}$, Bremen, Germany) employing ethanol-formic acid extraction. We identified the isolate as $S$. moniliformis 